\title{
Presentation of systemic lupus erythematosus (SLE) in emergency department: a case report
}

Natália Fernandes ${ }^{1}$, Guilherme Gomes ${ }^{1,3}$ and Carlos Capela1,2,3*

\begin{abstract}
Background: Abrupt and life-threatening presentations in connective tissue diseases (CTD) are rarely reported. Their early recognition and specific management could change course disease. SLE is a multisystem inflammatory disease that is often difficult to diagnose in the emergency department (ED).

Case presentation: A 26-year-old woman presented to the ED with a 48 hour history of progressive dispnea, generalized edema and left lower chest pain with non-productive cough. On examination, patient was feeling very ill, afebrile, tachycardic, tachypneic and a peripheral oxygen saturation of $94 \%$ on $40 \%$ supplemented oxygen with raised jugular venous pressure was noted. Intermittently, she presented an obtunded state of consciousness. A large pericardial, pleural and abdominal effusion was confirmed and a broad differential diagnosis was made. The patient had a 6 months history of inflammatory polyarthralgias involving initially interphalangeal joints, evolving, sometime later, the knees and elbows bilaterally and she was started glucocorticoids. 12 days before admission, she had had symptoms of a urethritis episode. In the context of an immunosupressed patient, with initial focal urologic complains, evidence of multiorgan dysfunction and a picture resembling a distributive shock, dictated a low threshold for sepsis.

Conclusions: Separating an acute episode of SLE from sepsis, on emergency grounds, can even be the most challenging decision. In the ED, acute life-threatening and multisystemic conditions should arise the suspicion of autoimmune diseases, particularly SLE.
\end{abstract}

\section{Background}

Abrupt and life-threatening presentations in connective tissue diseases (CTD) are rarely reported. Their early recognition and specific management could change course disease. SLE is a multisystem inflammatory disease that is often difficult to diagnose in the emergency department [1]. To the emergencist, it's important to consider SLE as possibility, when faced with a patient with symptoms and/or signs suggesting a multisystem disorder. Emergent complications of SLE are managed in the usual manner the most described being: strokes, acute myocardial infarctions, hemoptysis, respiratory distress and pulmonary emboli [2-4]. Other complications, such as pericardial tamponade [1], pulmonary

\footnotetext{
* Correspondence: carloscapela@ecsaude.uminho.pt

'Department of Internal Medicine, Hospital of Braga, Braga, Portugal ${ }^{2}$ Life and Health Sciences Research Institute, School of Health Sciences, University of Minho, Braga, Portugal

Full list of author information is available at the end of the article
}

hemorrhage, renal failure, or cerebritis should be managed with appropriate subspecialist consultation.

\section{Case presentation}

A 26-year-old Portuguese woman presented to the emergence department with a 48 hour history of progressive dispnea, generalized edema and left lower chest pain with non-productive cough. The patient had a 6 months history of inflammatory polyarthralgias involving initially interphalangeal joints, evolving, at some time later, the knees and elbows bilaterally. After ongoing rheumatologist evaluation, she started prednisolone $10 \mathrm{mg}$ qd and hydroxychloroquine $400 \mathrm{mg} \mathrm{qd}$, while waiting laboratory results. 12 days before admission, she had had symptoms of a urethritis episode, associated with unexplained anorexia and asthenia, which led her to suspend the therapeutic, even against medical advice. On examination, patient was feeling very ill, afebrile, with tachycardia (144 bpm), tachypnea (34/min), blood pressure 143/ $82 \mathrm{mmHg}$, peripheral oxygen saturation of $94 \%$ on $40 \%$

\section{Biomed Central}


oxygen and raised jugular venous pressure. Intermittently she presented an obtunded state of consciousness. Aside a diffuse moderate edema and a livedoid skin discoloration, an erythematous rash over the cheeks and nasal bridge was noted. On auscultation heart sounds were found to be diminished and diffuse coarse crackles were noted on both lungs, with depressed vocal transmission in right basal thorax. Abdominal examination revealed moderate hepatomegaly and ascites. The electrocardiogram showed atrial fibrillation and low voltage QRS complexes. On chest roentgenogram (Figure 1) cardiomegaly and right pleural effusion were evident. Initial arterial blood gas showed metabolic acidosis (pH-7.134, PCO2-18 mm Hg, PO2-85 $\mathrm{mm} \mathrm{Hg}$, and HCO3-6 mEq/L). Intravenous fluid replacement was started, blood and urine were sent for culture and treatment was started with empiric antibiotics (ceftriaxone $2 \mathrm{~g}$ iv id plus ciprofloxacin $400 \mathrm{mg}$ iv bid) and methylprednisolone $1 \mathrm{~g}$ iv bolus for 3 days. Patient was admitted to a high-dependency unit (HDU) for further evaluation, monitoring and support. An ultrasound of the heart showed a large circumferential pericardial effusion without signs of tamponade, which to the consulted assistant cardiologist merit only monitoring. Complementary CT scan (Figures 2 and 3) excluded pulmonary embolism or other thrombotic events, revealed an enlarged and homogeneous liver and confirmed pleuropericardial effusion and ascites. The laboratory survey revealed a white blood cell count (WBC) of 5.300 cells/mm3, with $70 \%$ polymorphonucleated cells (PMNs), a platelet count of 417.000 per $\mathrm{mm} 3$ and hemoglobin $7,8 \mathrm{~g} / \mathrm{dL}$. Her INR was 2.4. An extended metabolic and liver panel demonstrated: sodium $131 \mathrm{mmol} / \mathrm{L}, \mathrm{BUN}$ $38.4 \mathrm{mg} / \mathrm{dL}$, creatinine $1.4 \mathrm{mg} / \mathrm{dL}$, total bilirubin $0.62 \mathrm{mg} /$ $\mathrm{dL}$, AST $401 \mathrm{U} / \mathrm{L}$, ALT $85 \mathrm{U} / \mathrm{L}$, and alkaline phosphatase $128 \mathrm{U} / \mathrm{L}$. Ammonia was $38 \mu \mathrm{mol} / \mathrm{L}$. C reactive protein $160 \mathrm{mg} / \mathrm{l}$ and ESR $87 \mathrm{~mm} / \mathrm{h}$. Urine evaluation

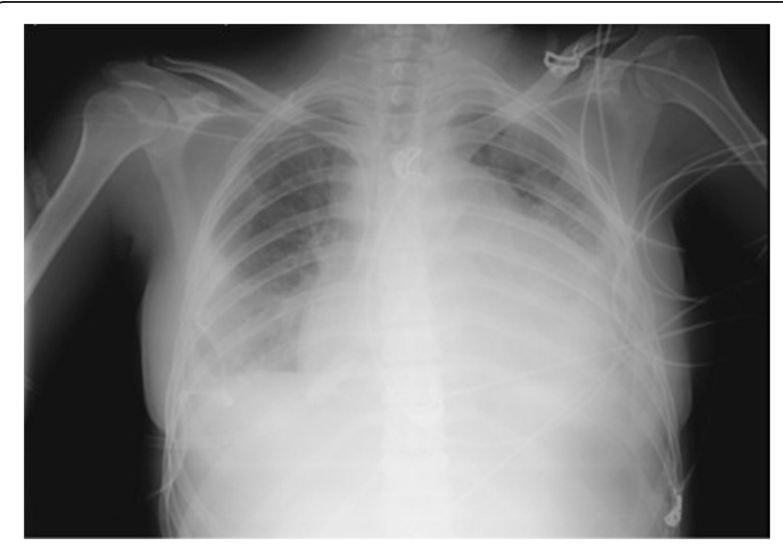

Figure 1 Chest roentgenogram showing cardiomegaly and right pleural effusion.

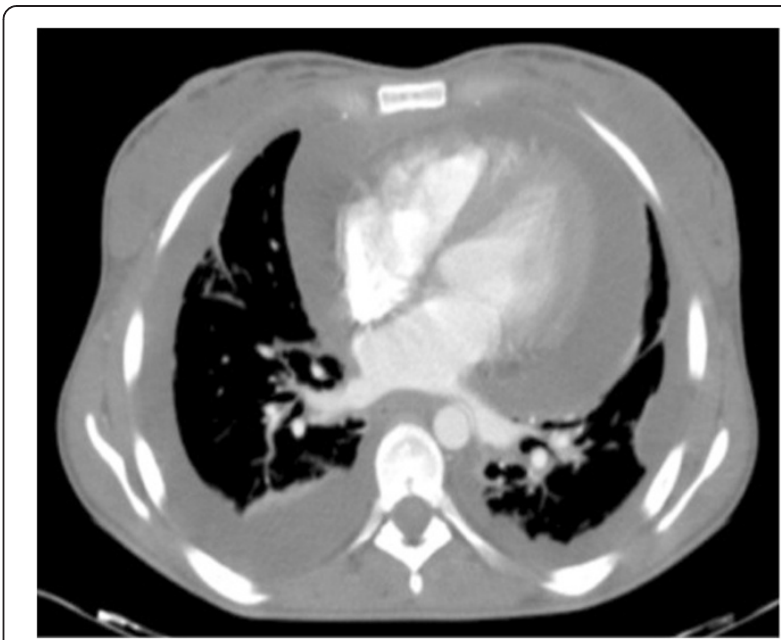

Figure 2 CT scan showing pleura-pericardial effusion.

demonstrates $>50$ leucocytes and erythrocytes per highpower field, associated with proteinuria $>75 \mathrm{mg} / \mathrm{dL}$ Meanwhile, an immunologic panel, done 1 month earlier, was sent to us, showing: polyclonal hypergammaglobulinemia; positive ANA (1:160), anti-dsDNA antibodies (75 UI/mL) with positivity to anti SSA, SSB and Histone. Pleural fluid analysis showed an exsudate with no bacteria on a Gram stain. By the 2nd HDU day patient was feeling much better with remarkable edema regression. Blood gas normalized. The microbiologic results of the blood, pleural fluid and urine cultures became negative and antibiotherapy was suspended. Immunological panel revealed frank hypocomplementemia (C3 <1 UI; C4 - 9 UI; CH50 <10 UI); ANA (1:320), anti-dsDNA antibodies (175 UI/mL) with persisting positivity to anti SSA, SSB and Histone, as well as hypergammaglobulinemia and a direct positive Coombs test. A 24 hour urine collection demonstrates

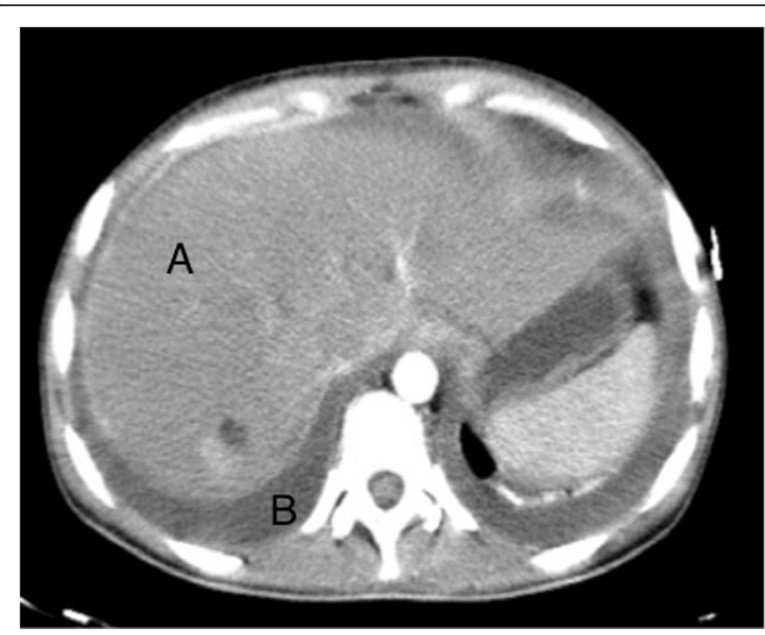

Figure 3 An enlarged liver and ascites. CT scan showing an enlarged and homogeneous liver (A) and ascites (B). 
$2,1 \mathrm{~g}$ proteins. The patient was discharge by the 10th hospital day, on a therapeutic regimen of $60 \mathrm{mg} /$ day of prednisolone plus hydroxychloroquine $400 \mathrm{mg} /$ day, after an arrangement with the nephrologic clinic to eventually proceed to a renal biopsy.

\section{Conclusions}

In this patient, SLE diagnostic criteria were accomplished when malar rash, polyserositis and positive immunology were summed to the previous described anamnestic features. All clinical and laboratory parameters pointed to a very active clinical process. As so, a true flare or a first full presentation of SLE were both tentative hypothesis, considering the short duration of the disease since she first call for medical attention and voluntary suspension of therapy. Such an explosive clinical presentation, in the context of an immunosupressed patient, with initial focal urologic complains, evidence of multiorgan dysfunction and a picture resembling a distributive shock, dictated a low threshold for sepsis and the decision to treat with antimicrobials until infection was surely excluded. This option was supported by generalized knowledge that, in sepsis, the prognosis varies with the elapsed time and the precocity and aggressivity of the initial measures. Separating an acute episode of SLE from sepsis, on emergency grounds, can even be the most challenging decision. We have also seen such a dramatic clinical picture in young people, particularly women, with catastrophic antiphospholypid syndrome, which led us to consider it in this patient. In retrospect, the full immunossupression with glucocorticoids aborted the potential negative consequences of the active SLE, and allowed a conservative approach to a potential lifethreatning consequence of a large pericardial effusion [5,6]. It remain unanswered if it was a real flare or the full expression of a progressing lupus, and perhaps it would turn an academic question in face of pressing clinical situations like this one, where treating with a structured reasoning, considering acute presentations of connective tissue disease and its complications will be more important and rewarding.

In the emergency department, acute life-threatening and multisystemic conditions should arise the suspicion of autoimmune diseases, particularly SLE. Circulating immune complexes and autoantibodies with multiples specificities, diffusely deposit and attack a multitude of organic targets, activating complement and mounting a full inflammatory response, provide a substract for the proteiform clinical e laboratorial expression of this disease. Usually, albeit impressive and frightening, the different manifestations can be successfully managed by adequate, early and full immunossupression [7].

\section{Consent}

Written informed consent was obtained from the patient for publication of this case report and any accompanying images. A copy of the written consent is available for review by the Editor-in-Chief of this journal.

\section{Competing interests}

The authors declare that they have no competing interests.

\section{Authors' contribution}

NF and CC treated the patient and wrote the case report; GG and CC supervised the writing and made some major changes in manuscript after reviewing the first versions. All authors read and approved the final manuscript.

\section{Author details}

'Department of Internal Medicine, Hospital of Braga, Braga, Portugal. ${ }^{2}$ Life and Health Sciences Research Institute, School of Health Sciences, University of Minho, Braga, Portugal. ${ }^{3}$ Autoimmune Diseases - Department of Internal Medicine, Hospital of Braga, Braga, Portugal.

Received: 27 March 2013 Accepted: 24 April 2013

Published: 5 May 2013

\section{References}

1. Rosenbaum E, Krebs E, Cohen M, Tiliakos A, Derk CT: The spectrum of clinical manifestations, outcome and treatment of pericardial tamponade in patients with systemic lupus erythematosus: a retrospective study and literature review. Lupus 2009, 18(7):608-612.

2. Urowitz MB, Gladman D, Ibañez D, Bae SC, Sanchez-Guerrero J, Gordon C, Clarke A, Bernatsky S, Fortin PR, Hanly JG, Wallace DJ, Isenberg D, Rahman A, Alarcón GS, Merrill JT, Ginzler E, Khamashta M, Nived O, Sturfelt G, Bruce IN, Steinsson K, Manzi S, Ramsey-Goldman R, Dooley MA, Zoma A, Kalunian K, Ramos M, Van Vollenhoven RF, Aranow C, Stoll T, et al: Systemic lupus international collaborating clinics: atherosclerotic vascular events in a multinational inception cohort of systemic lupus erythematosus. Arthritis Care Res (Hoboken) 2010, 62(6):881-887.

3. Shah MA, Shah AM, Krishnan E: Poor outcomes after acute myocardial infarction in systemic lupus erythematosus. J Rheumatol 2009, 36(3):570-575

4. Mok CC, Tang SS, To CH, Petri M: Incidence and risk factors of thromboembolism in systemic lupus erythematosus: a comparison of three ethnic groups. Arthritis Rheum 2005, 52(9):2774-2782.

5. Mon BL, Mok CC: Serositis related to systemic lupus erythematosus: prevalence and outcome. Lupus 2005, 14(10):822-826.

6. Ramos B, Carretero C, Fontin G, Vasquez R: Pericardial effusion as the only first clinical manifestation of systemic lupus erythematosus. An Med Interna 2006, 23(2):80-82.

7. Panopalis P, Gillis JZ, Yazdany J, Trupin L, Hersh A, Julian L, Criswell LA, Katz $P$, Yelin E: Frequent use of the emergency department among persons with systemic lupus erythematosus. Arthritis Care Res (Hoboken) 2010, 62(3):401-408.

doi:10.1186/1756-0500-6-181

Cite this article as: Fernandes et al:: Presentation of systemic lupus erythematosus (SLE) in emergency department: a case report. BMC Research Notes 2013 6:181.

\section{Submit your next manuscript to BioMed Central and take full advantage of:}

- Convenient online submission

- Thorough peer review

- No space constraints or color figure charges

- Immediate publication on acceptance

- Inclusion in PubMed, CAS, Scopus and Google Scholar

- Research which is freely available for redistribution 